\title{
Iodine, milk, and the elimination of endemic goitre in Britain: the story of an accidental public health triumph
}

\author{
D I W Phillips
}

\begin{abstract}
Objective-To determine how iodine deficiency and endemic goitre disappeared in Britain.

Design-Review of surveys of endemic goitre and iodine nutrition.

Main results - Endemic goitre was widespread in Britain but has declined, most notably since the 1960 s. Its disappearance was probably due to changes in farming practice, especially iodine supplementation in dairy herds which has resulted in iodine contamination of milk and dairy produce.

Conclusions-Although iodization of dairy herds offers an indirect method of counteracting iodine deficiency, it is haphazard and there should be careful and continuous monitoring of iodine intakes in the population.
\end{abstract}

(f Epidemiol Community Health 1997;51:391-393)

Although endemic goitre and other diseases caused by iodine deficiency remain a significant global health problem, few doctors practising in the 1990s will recall that endemic goitre was at one time widespread in Britain. Its elimination is the story of an unplanned and accidental public health triumph. While many other countries introduced national iodization programmes to eliminate iodine deficiency by adding iodine to salt or bread, this was never carried out in Britain. Yet endemic goitre has disappeared and iodine intakes in the UK have risen progressively during the last half century. The most reasonable explanation seems to be that changes in farming practice which led to iodine contamination of milk and dairy produce together with the policy of successive governments in encouraging milk consumption led to the eradication of this age old disease.

Metabolic

Programming Group,

Medical Research

Council,

Environmental

Epidemiology Unit,

University of

Southampton,

Southampton General

Hospital, Tremona

Road, Southampton

SO16 6YD.

D I W Phillips

Correspondence to:

Dr D I W Phillips.

Accepted for publication

November 1996

\section{Endemic goitre in Britain}

In his 1836, Treatise on English Bronchocoele, Inglis recorded that endemic goitre was as common in the Yorkshire dales as in Geneva or any of the Alpine valleys. ${ }^{1}$ Children could be seen at play with pieces of black velvet tied around their necks to charm away the goitre evil. Other early records reported that goitre and even cretinism, usually associated with severe iodine deficiency, could be found in several English Counties including Norfolk, Monmouthshire, and Cornwall. ${ }^{2}$ Cretinism was said to be no- torious in Chiselborough, Somerset. ${ }^{3}$ By the turn of the century an English goitre belt was recognised which extended from the West Country through Somerset into the Cotswold and Chiltern Hills and northwards into Derbyshire and the Peak District. There were well defined offshoots affecting both north and south Wales (fig 1). In 1924, a survey of 12 year old schoolchildren in England and Wales was carried out by school medical officers at the request of the Board of Education. ${ }^{4}$ This study is remarkable, not least for its sheer size comprising observations on 375000 children. It confirmed the geographical pattern of the disease shown by previous studies and revealed a high prevalence of visible goitre (up to $30 \%$ in some communities) which led to calls for a national iodization programme. The war of 1939-45 brought the subject into new prominence because goitre appeared to be unusually common in young women drafted into factories for war work. The Medical Research Council (MRC) carried out several special surveys which showed visible goitre to be present in $50 \%$ of the adult women in Hook Norton, Oxfordshire, $43 \%$ of girls in Sherborne, Dorset; and in $26 \%$ of boys and girls in St Albans, Hertfordshire. ${ }^{5}$ In contrast, only $2 \%$ of children showed thyroid enlargement in Maldon, Essex where the drinking water is rich in iodine. In 1944 and again in 1948 the MRC urged the general adoption of iodized salt throughout the UK as a means of preventing goitre but no action followed. ${ }^{56}$

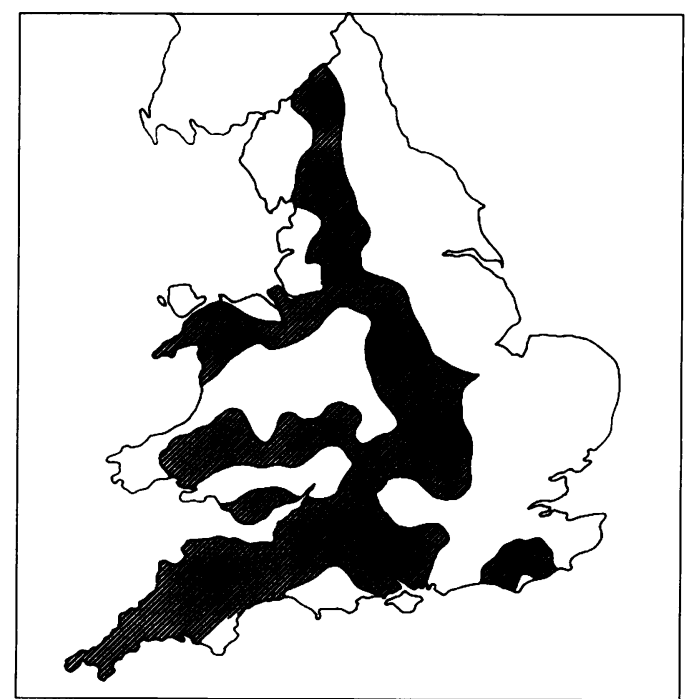

Figure 1 Areas of England and Wales where endemic goitre has been prevalent in the past. ${ }^{24}$ 
A number of ad hoc surveys carried out in subsequent years showed that thyroid enlargement continued in many areas well into the 1960s. Schools in north Oxfordshire, which had been included in the 1948 MRC survey, were resurveyed in 1958 using the same methods and classification. ${ }^{7}$ Goitre rates were similar in boys but had actually increased in girls from $27 \%$ in 1948 to $40 \%$ in 1958 . Later surveys showed goitre to be still present during the early 1960s in Sheffield and South Wales ${ }^{89}$ and detailed metabolic studies of patients presenting with non-toxic thyroid enlargement in Glasgow showed that they had low dietary iodine intake and low plasma inorganic iodine concentrations. ${ }^{10}$ Subsequently, the disease appears to have declined and a 1990 survey showed that thyroid enlargement was no longer detectable in schoolchildren in a traditionally iodine deficient area of South Wales. ${ }^{11}$

\section{The iodization and marketing of milk in Britain}

Research during the 1920 s showed that iodine supplementation of livestock could improve their reproductive performance. ${ }^{12}$ This provided an economic incentive for the iodine supplementation of dairy herds, which was achieved by providing iodized salt licks for cattle (introduced by Boots in 1928) and subsequently the use of iodine enriched cattle feed (marketed by Spillers in 1937). The result was a spectacular rise in the iodine content of milk, particularly during the winter months when pasture is in short supply and cattle are dependent on iodine rich artificial feed. The use of iodinated casein, given to cows as a lactation promoter, and iodophor disinfectants, used for cleaning teats and bulk milk tankers, also contributed to the iodine contamination of milk. ${ }^{13}$

In parallel with this increase in iodine content, successive governments put into effect policies to increase the consumption of milk and dairy produce. Before the 1930s milk had been a luxury only affordable by wealthier families. A survey in 1932 found a mean intake of only 3.1 pints per week. ${ }^{14}$ The subsequent establishment of the Milk Marketing Board

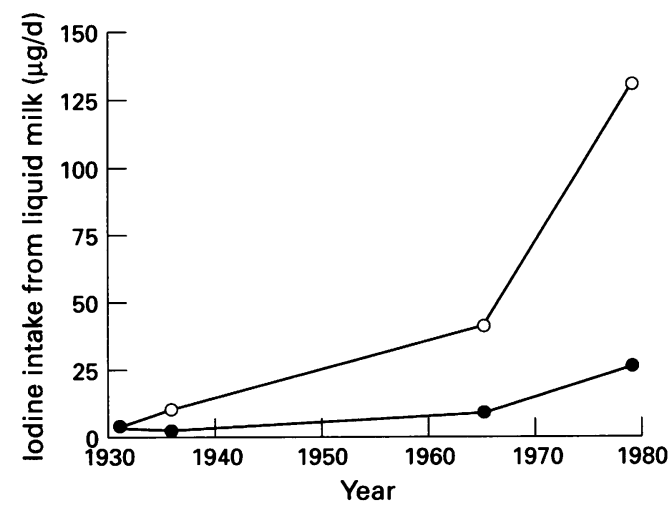
Figure 2 Average daily iodine intake from milk in the
UK based on surveys of milk intake ${ }^{14}$ and the iodine UK based on surveys of milk intake ${ }^{14}$ and the iodine
content of milk ${ }^{132223}$ between 1931 and 1980 . Closed circles represent Summer samples and open circles Winter samples.

\section{KEY POINTS}

- Iodine deficiency used to be widespread in Britain.

- Although Britain has never had mandatory iodization of salt and other foods, iodine intake has increased, especially during the past 30 years, and iodine deficiency has largely disappeared.

- Increased iodine intake is mainly due to changes in farming practice that have resulted in iodine contamination of milk and dairy produce.

- If maintenance of adequate iodine intake is to depend on farming practice, it is essential that iodine nutrition is monitored in the future.

and the Milk Act (1934) and The National Milk Scheme (1940), which provided free milk or at a subsidised price for all expectant mothers and young children, greatly boosted consumption.

By the early 1950s average liquid milk consumption had nearly doubled. ${ }^{14}$ In figure 2 data on milk consumption have been combined with published analyses of its iodine content to show how the amount of iodine provided by average milk consumption in the UK has increased since 1931. By the 1980s the iodine content of milk during the winter was such that milk alone could almost satisfy the recommended daily requirement of $150 \mu \mathrm{g} /$ day. ${ }^{13}$ Indeed, the iodine content in some milk samples was so high that this led to concerns about possible toxic effects. ${ }^{15}$ The increase in the iodine content of milk and related dairy products is likely to have been the major explanation of the threefold rise in dietary iodine intakes, from $80 \mu \mathrm{g}$ to $255 \mu \mathrm{g} /$ day, which occurred between 1952 and $1982 .{ }^{1617}$ Iodine intakes were also boosted by the iodine enrichment of meat and eggs, probably due to the same processes of spillover from the use of iodine in animal feeds. ${ }^{12}$ It is noteworthy, however, that over the same period the consumption of traditional iodine rich foods such as fish and sea food declined. ${ }^{13}$ Other northern European countries, particularly Scandinavia, have also benefited from iodine in milk and dairy produce because of the use of iodine rich feeds throughout the long winters. ${ }^{18}$ This may explain why iodine deficiency has declined in northern Europe but not in southern Europe where pasture is available for a greater part of the year and artificial feedstuffs are less often used. ${ }^{19}$

\section{Iodine induced thyrotoxicosis}

Iodization is not without its side effects and it has been known for many years that an increase in the incidence of hyperthyroidism often occurred after iodization. It usually affected older subjects who had a longstanding goitre and is due to increased sensitivity of the thyroid gland to iodine in amounts which would be well tolerated by normal subjects. There is evidence that this has occurred in Britain. Mortality from thyrotoxicosis peaked in the decade 1931-40, 
and both the mortality and incidence of thyrotoxicosis due to toxic multinodular goitre have remained highest in those areas of Britain shown in figure 1 which once had endemic goitre. ${ }^{2021}$ While the increase in dietary iodine in these iodine deficient areas of Britain has benefited the young by eradicating goitre, the price may have been of precipitating thyrotoxicosis in older men and women in the same areas.

\section{Conclusion}

Countries with endemic iodine deficiency have tended to solve the problem by the compulsory iodization of staple foodstuffs, for example bread or salt. The British experience, however, suggests that the same result can be achieved by ensuring that dairy herds are iodine replete and allowing the resulting iodine contamination of milk and dairy produce to increase human iodine intakes. While compulsory iodization of salt or bread has the advantage that it can be precisely controlled, consumer opposition allied with stringent regulations to control the use of food additives has tended to prevent iodization in recent years, most notably in Germany. ${ }^{25}$ Allowing the spillover of iodine from dairy herds to effect iodization offers an alternative but has the disadvantage of being considerably more haphazard as the amounts of iodine entering the human food chain will depend on both farming practice and the levels of consumption of key foodstuffs, in particular liquid milk. As this solution has been adopted by default in Britain, it is nevertheless essential that iodine intakes are carefully monitored to ensure that they remain adequate to prevent the re-emergence of iodine deficiency and its adverse health consequences.

Funding: Medical Research Council

Conflicts of interest: none.

1 Inglis J. Treatise on English bronchocoele, with a few remarks on the use of iodine and its compounds. London, 1838

2 Kelly FC, Snedden WW. Prevalence and geographical distribution of endemic goitre. In : Endemic goitre. WHO. Monograph Series No 44. Geneva: WHO, 1960:105-9.

3 Pharoah POD, Delange F, Fierro-Benitez R, Stanbury JB. Endemic cretinism. In: Stanbury JB, Hetzel BS eds. En- demic goitre and endemic cretinism. New York: Wiley, 1980: 395-421.

4 Stocks P. Goitre in the English school child. Quart $\mathrm{f} \mathrm{Med}$ 1928;21:223-75.

5 Murray MM, Ryle JA, Simpson BW, Wilson DC. Thyroid enlargement and other changes related to the mineral content of drinking water (with a note on goitre prophylaxis). MRC Memorandum No18. London: MRC, 1948.

6 Medical Research Council Goitre Subcommittee. Endemic goitre in England. Argument for preventive action. Lancet goitre in Englan

7 Hughes DE, Rodgers K, Wilson DC. Thyroid enlargement in schoolchildren of North Oxfordshire. BMF 1959;1 $280-81$.

8 Trotter WR, Cochrane AL, Benjamin IT, Miall WE. A goitre survey in the Vale of Glamorgan. Br f Prev Soc Med 1962;16:16-21.

9 Kilpatrick R, Milne JS, Rushbrooke M, Wilson ESB, Wilson GM. A survey of thyroid enlargement in two general practices in Great Britain. BMF 1963;1:29-34

10 Wayne EJ, Koutras DA, Alexander WD. Clinical aspects of iodine metabolism. Oxford: Blackwell, 1964:101-110.

11 Lazarus JH, Phillips DIW, Parkes AB, Smyth PPA, Hall R Status of iodine nutrition in the United Kingdom. In Dtatus of iodin nutring Deds. Iodine deficiency in Europe: a continuing concern. New York: Plenum Press,

12 Underwood EJ. Iodine. In: The mineral nutrition of livestock. Slough: Commonwealth Agriculture Bureau, 1984, 84 85.

13 Wenlock RW. Changing patterns of dietary iodine intake in Britain. In: Dietary iodine and other aetiological factors in hyperthyroidism. Southampton: MRC Conference Report 1987:1-6.

14 Drummond JC and Wilbraham A. Milk consumption and marketing 1927-1958. In: The Englishman's food. London: Cape, 1969.

15 Phillips DIW, Nelson M, Barker DJP, Morris JA, Wood TJ. Iodine in milk and the incidence of thyrotoxicosis in England. Clin Endocrinol 1988;28:61-6.

16 Chilean Iodine Educational Bureau. Iodine content of foods. London: Shenval Press, 1952.

17 Wenlock RW, Buss DH, Moxon RE, Bunton NG. Trace nutrients 4. Iodine in British food. Br 7 Nutr 1982;47: nutrients

18 Renaa T, Staveland K. An investigation of the concentration of iodine in milk from different locations in Norway during the 12 month period July 1971-June 1972. Tidsskrift for den Norske Laegeforening 1974;94:990-93.

19 Subcommittee for the study of endemic goitre and iodine deficiency of the European Thyroid Association. Goitre and iodine deficiency in Europe. Lancet 1985;i:1289-93.

20 Barker DJP, Phillips DIW. Current incidence of thyrotoxicosis and past prevalence of goitre in 12 British towns. Lancet 1984;ii:567-70.

21 Phillips DIW, Barker DJP, Winter PD, Osmond C. Mortality from thyrotoxicosis in England and Wales and its asfrom thyrotoxicosis in Sociation with the previous prevalence of endemic

22 Committee on Iodine Deficiency and Thyroid Disease. The relationship of the iodine contents of water, milk and pasture to the occurrence of endemic goitre in two districts of England. to the occurrence of endemic goitre in two districts of England. 1936 .

23 Orr JB. Iodine supply and the incidence of endemic goitre. MRC Special Report Series No 154. London: HMSO, 1931.

24 Ministry of Agriculture, Fisheries and Food. Household food consumption and expenditure 1990, with a study of trends over the period 1940-1990. London: HMSO, 1991.

25 Pfannensteil P. Direct and indirect costs caused by continuous iodine deficiency. In Hall $\mathrm{R}$, Köbberling $\mathrm{J}$ eds. Thyroid diseases associated with iodine deficiency and excess. Raven Press: New York, 1985:457-463. 